council of the Royal College of General Practitioners and the General Medical Services Committee (Wales).

In overall terms our deputation feared that the general principles of the referral system were compromised, access to specialist psychiatric services was ill defined, and the declared role of the mental health team in primary care could lead only to fragmentation and confusion. Furthermore, the contractual obligations of the general practitioner were totally bypassed.

The deputation received a sympathetic hearing, and it was with great disappointment that we read the final paper, Mental Health Services, a Strategy for Wales, issued in June 1989. Little has changed from that set out in the consultation document, and we are convinced that if the recommendations of this paper are implemented the task of treating psychiatric disorder in Wales is likely to be muddled and expensive.

R C HUMPHREYS

Crickhowell,

Powys NP8 1AP

N C H STOTT Cardiff CF4 4XN

1 Shepherd M. Primary care of patients with mental disorder in the community. Br Med F 1989;299:666-9. (9 September.)

\section{Rape and subsequent seroconversion to HIV}

SIR, - The paper by Dr S Murphy and colleagues highlights the potential risks and worries for women who have been sexually assaulted during the current phase of the HIV epidemic. ${ }^{1}$ If we assume that such assailants are heterosexual men the overall risk of transmission is likely to be small in view of the present low carriage rate for the virus among this group in Britain.' In addition, vagina intercourse is possibly a less likely mode of transmission than anal intercourse. ${ }^{3}$ The situation for male victims of sexual assault may, however, be different.

Male "rape" as a legal term does not exist in the United Kingdom, as rape specifies forcible vagina penetration. Furthermore, male sexual assault is not recognised as a distinct entity within the 1976 Sexual Offences (Amendment) Act. ${ }^{4}$ This may well have consequences for the number of cases reported and for public awareness of such events. ${ }^{5}$ Documented cases of sexual assault of men by women have been reported, ${ }^{6}$ but it is generally thought that men are more commonly assaulted by other men.

In the United States it has been estimated that only $10-20 \%$ of all sexual assaults are ever reported. In addition, there is some evidence to suggest that male victims are more reluctant to come forward than their female counterparts, possibly related to the fear of being labelled as homosexual ${ }^{8}$ or to society's concept that a "real man" cannot be raped.'

Partly as a consequence of its legal non-existence there are no reliable figures of the frequency and nature of male sexual assault in Britain. The only organisation providing care for victims of male sexual assault in Britain at present is "Survivors," a service run by volunteers to which various government and charitable agencies refer their clients The service provides a telephone help line (currently answering just over 100 inquiries a month) together with counselling and support. No studies to date have assessed the risk of sexually acquired infection in male victims of assault, ${ }^{9}$ bu of 512 victims known to Survivors in 1988, 24 of 73 who sought medical advice were diagnosed as having a sexually transmitted disease presumed be consequent on their assault. Data on HIV seroconversion are not available, but 148 of the 512 victims reported skin or mucosal bleeding, and 278 expressed concern about the possibility of transmission of HIV. In 92 of the cases the assailant deliberately threatened the victim with the possibility of contracting HIV infection as a consequence of the assault.

It has been suggested that between $50 \%{ }^{10}$ and $82 \%^{4}$ of assailants of male victims are either homosexual or bisexual. The assailants are therefore in relatively higher risk groups for HIV infection than heterosexual assailants of women. Futhermore, anal penetration, bloody non-genital violence, and multiple assailants are more likely when the victim is male.

Rape treatment centres have been set up primarily for female victims and may lack the skills to deal with men. We believe that an increased level of awareness of male sexual assault is needed among the general public and especially by health care professionals to encourage victims to come forward. Only when this happens can the scale of the problem be fully grasped and appropriate treatment provided.

RICHARD HILLMAN Division of Sexually Transmitted Diseases, Clinical Research Centre,

Harrow,

Middlesex

Survivors,

London WC1

NIGEL O'MARA

1 Murphy S, Kitchen V, Harris JRW, Forster SM. Rape and subsequent seroconversion to HIV. Br Med f 1989;299.718. (16 September.)

2 PHLS Communicable Disease Surveillance Centre. Human immunodeficiency virus (HIV -1$)$ antibody reports. United Kingdom; weeks 84/45-89/39. Communicable Disease Reports 1989;40:3.

3 Padian NS. Heterosexual transmission of acquired immunodeficiency syndrome: international perspectives and national projections. Rev Infect Dis 1987;9:947-60.

4 Mezey G, King $M$. The effects of sexual assault on men: a survey of 22 victims. Psychol Med 1989;19:205-9.

Mezey G, King M. Male victims of sexual assault. Med Sci Law 987;27:122-4

6 Schiff AF. Examination and treatment of the male rape victim. South Med f 1980;73:1498-502.

7 Geist FR. Sexually related trauma. Emerg Med Clin North Am 1988;6:439-66.

8 Kaufman A, Divasto P, Jackson R, Voorhees D, Christy J. Male rape victims: noninstitutionalised assault. Am f Psychiatry 1980;137:221-3.

9 Glaser JB, Hammerschlag MR, McCormack WM. Epidemiology of sexually transmitted diseases in rape victims. Req Infect Dis 1989;11:246-54.

10 Groth AN, Burgess AW. Male rape: offenders and victims. Am $\mathcal{F}$ Psychiatry 1980;137:806-10.

\section{Passive smoking and cardiorespiratory health in Scotland}

SIR,-Mr Peter N Lee' implies that our observation of increased risk for four respiratory symptoms and two cardiovascular symptoms, mortality from lung cancer, mortality from ischaemic heart disease, all causes of death related to smoking, and mortality from all causes in passive smokers compared with controls ${ }^{2}$ can be explained by bias-that of smokers declaring themselves to be lifelong non-smokers. He cites (presumably) lung cancer, for which if, as he supposes, no increased risk is associated with exposure to environmental tobacco smoke and the "true" risk is increased 20 times in active smokers,
$2 \%$ of smokers denying smoking would result in observed relative risks of 1.74 for passive smokers and 6.90 for active smokers. This is illustrated in his table, using the distribution of subjects in the smoking groups defined in our study. But why does he use only men and ignore women when our analysis and results were based on both sexes and women comprised $84.2 \%$ of our passive smokers? If he had included women $5.0 \%$ of passive smokers and $3.9 \%$ of controls would have smoked (table I)-quite different from the figures of $15.6 \%$ and $6.8 \%$ respectively presented in his table. Our figures in turn produce an observed relative risk of 1.12 for passive smoking (substantially less than the 1.74 he quotes by selecting only men) and considerably less than our study finding of 2.41 for lung cancer among passive smokers. Clearly, misclassification owing to the $2 \%$ rate of denial of smoking he suggests does not explain our finding.

In addition, higher rates of denial of smoking do not produce sufficient bias to explain our risk for lung cancer. Table II presents the effect on the basis of a "true" relative risk of 20 for active smoking and 1 for passive smoking and of rates of denial varying from $1 \%$ to $10 \%$. Two facts emerge: firstly, the bias in the relative risk for passive smokers does not increase linearly as the rate of denial increases, it flattens considerably; secondly, the observed relative risk for active smokers diminishes rapidly as the rate of denial increases.

TABLE II-Relative risks for passive and active smoking for varying rates of smoking

\begin{tabular}{ccc}
\hline \multirow{2}{*}{$\begin{array}{c}\text { Rate of denial } \\
(\%)\end{array}$} & \multicolumn{2}{c}{ Observed relative risk } \\
\cline { 2 - 3 } & Passive smokers & Active smokers \\
\hline 1 & 1.07 & 13.95 \\
2 & 1.12 & 10.67 \\
3 & 1.15 & 8.61 \\
4 & 1.18 & 7.17 \\
5 & 1.19 & 6.14 \\
6 & 1.20 & 5.35 \\
7 & 1.21 & 4.73 \\
8 & 1.22 & 4.23 \\
9 & 1.23 & 3.82 \\
10 & 1.23 & 3.47 \\
\hline
\end{tabular}

This is important, as by comparing the observed relative risk for active smokers from the table with the relative risk found in the study an upper bound can be defined for the rate of denial. The study relative risk for active smokers compared with lifelong non-smokers is $5 \cdot 85$. This would be incompatible with rates of denial greater than $5 \%$. Therefore, the largest relative risk to be expected among passive smokers due to this form of bias when the "true" risk is unity is $1 \cdot 20$. A relative risk of 2.41 was found in our study.

Again, the same approach applied to ischaemic heart disease assuming a "true" relative risk of 3 for active smokers and 1 for passive smokers and a rate of denial of smoking of $5 \%$ produces an observed relative risk of 1.05 for passive smokers and 2.42 for active smokers. Thus if the relative risk for active smokers is considerably less than 20 , as in all the conditions we considered other than lung cancer, the effect of misclassification is to produce only small biases in the relative risk for passive smokers. Our risks for each of the respiratory symptoms, cardiovascular symptoms, and cate-

TABLE I - Differential misclassification caused by $2 \%$ of index subjects denying smoking regardless of cohabitee's smoking habits

\begin{tabular}{lcccc}
\hline $\begin{array}{l}\text { Exposure } \\
\text { group }\end{array}$ & $\begin{array}{c}\text { Observed } \\
\text { distribution } \dagger\end{array}$ & $\begin{array}{c}\text { "True" } \\
\text { distribution }\end{array}$ & $\begin{array}{c}\text { Effects of } \\
\text { denial }\end{array}$ & $\begin{array}{c}\text { Percentage who } \\
\text { have smoked }\end{array}$ \\
\hline Controls & 917 & 881 & +36 & $3 \cdot 9$ \\
Passive smokers & 1538 & 1461 & +77 & $5 \cdot 0$ \\
Single smokers & 1751 & 1787 & -36 & \\
Double smokers & 3791 & 3868 & -77 & \\
\hline
\end{tabular}

*As defined by Hole et al. ${ }^{2}+$ Data from table I of Hole et $a l .^{2}$ 
gories of mortality quoted are well in excess of that produced by the form of bias suggested. Also, as control subjects experience some level of environmental tobacco smoke ${ }^{23}$ our estimates of risk could be conservative.

$\mathrm{Mr}$ Lee misunderstands our use of urinary cotinine concentrations in passive smokers. We were using published data to establish whether our study had sufficient statistical power to detect the size of risk that might be expected among passive smokers. If $\mathrm{Mr}$ Lee is correct and urinary cotinine concentrations are equivalent to a lower dose than assumed then our decision not to rely solely on statistical significance as evidence of a genuine effect was definitely correct. Ours was a cohort study of a general population and was not subject to the biases associated with a case-control design. In addition, subjects reported their own smoking histories, and environmental exposure was based on record linkage of cohabitees, thereby avoiding the need to rely on self reporting of passive exposure.

Our observations on lung cancer may be based on only nine deaths but are consistent with the result of a meta-analysis ${ }^{2}$ combining 13 separate studies, which concluded that breathing other people's tobacco smoke causes lung cancer. The importance of our study lies in the estimates of risk for ischaemic heart disease (based on 84 deaths), all causes of death related to smoking (175 deaths), mortality from all causes (263 deaths), respiratory symptoms (292 cases), and cardiovascular symptoms (117 cases). The consistent increase in risks for such a wide variety of health outcomes from an unbiased prospective cohort study together with a dose-response relation in passive smokers strongly suggests that there is now a case to be answered against passive smoking that extends beyond the causation of lung cancer.

DAVID J HOLE CHARLES R GILLIS

West of Scotland Cancer Surveillance Unit,

Ruchill Hospital,

Glasgow G20 9NB

CAROL CHOPRA

VICTOR M HAWTHORNE

Department of Epidemiology,

University of Michigan,

Michigan,

United States

1 Lee PN. Passive smoking and cardiorespiratory health in Scotland. Br Med f 1989;299:742. (16 September.)

2 Hole DJ, Gillis CR, Chopra C, Hawthorne VM. Passive smoking

and cardiorespiratory health in' a general population in the west of Scotland. Br Med $\mathcal{F}$ 1989;299:423-7. (12 August.)

3 Wald NJ, Nanchalal K, Thompson SG, Cuckle HS. Does breathing other people's tobacco smoke cause lung cancer? $\mathrm{Br}$ Med f 1986;293:1217-22.

\section{Referrals from general practice to hospital outpatient departments}

SIR, - One aspect highlighted in the report by Drs John Emmanuel and Nigel Walker' is treatment of skin disorders in general practice. Proposals in the white paper are likely to encourage more minor surgery to be undertaken by general practitioners. This may be more cost effective (although our own experience indicates that this may not necessarily be so), but skin surgery should be undertaken in general practice only if the diagnosis is certainotherwise referrals may be increased rather than decreased as intended. We report two problems that resulted from inappropriate skin surgery in general practice.

A 49 year old woman had a pigmented lesion removed by curettage and cautery from her lower leg by her general practitioner. Histology showed malignant melanoma, but it was impossible to ascertain the depth of the tumour on the basis of the inadequately thin curettage specimen. The patient then had a wide excision and graft, but it is possible that she would not have required an extensive operation because narrow excision margins can sometimes be adequate for very thin melanomas.

In another patient, a 46 year old woman, a slightly raised nodule on the leg was treated by curettage and cautery by her general practitioner. Histology showed invasive squamous cell carcinoma and the patient was referred for further advice. Because it was difficult to know the adequacy of the initial treatment the patient was committed to prolonged follow up to exclude recurrence of the lesion.

PHILIP HARRISON

Department of Dermatology,

Beaumont Hospital,

Lancaster LA1 2JF

Department of Pathology,

Lancaster LA1 3RJ

1 Emmanuel J, Walter N. Referrals from general practice to hospital outpatient departments: a strategy for improvement. hospital outpatient departments: a strategy
BrMed f 1989;299:722-4. (16 September.)

\section{Provision of services}

SIR, - It seems to be the custom that when a specialist advisory committee pronounces on how services should be provided this is accepted, but there are occasions when someone needs to stand up and say "You are wrong."

The North West Thames ear, nose, and throat regional advisory subcommittee says that inpatient ear, nose, and throat services should be provided only in subregional specialist centres and not in the smaller district general hospitals. I have been the anaesthetist for three to four ear, nose, and throat lists per week for over 20 years and know that most of these operations are everyday bread and butter surgery and that over half are on children. Indeed the commonest paediatric operations are ear, nose, and throat - tonsils, glue ears, etc. These services have always been available at the local hospital and to say they should all go to subregional centres is tantamount to saying all hernias and ingrowing toenails should go to specialised units. Not only does this deprive patients of what I would call a core service but it has profound knock on effects on most other services in the district general hospital through the possible loss of recognition of anaesthetic jobs. Before someone brings out the old chestnut of "Make rotations" I will answer "Just you try to."

We are facing this situation in North West Hertfordshire District, where the loss of inpatient. ear, nose, and throat services will disadvantage our patients and could cause havoc with the hospital services as a whole. I am afraid that this may be only the beginning of specialist groups building their own little empires without regard to the patients and hospitals from whom they withdraw their services.

MARGARET E PICKERING-PICK

St Albans City Hospital

St Albans AL3 9XX

\section{Psychiatric illness among the homeless}

SIR,-Dr Max Marshall describes a high proportion of residents of Oxford hostels for the homeless as being "long term psychiatric patients" and implies that: they are deinstitutionalised long stay patients. ' Our findings, however, suggest that hostel residents with psychiatric disabilities may have had numerous yet relatively brief hospital admissions and include those sometimes referred to as "revolving door" patients.

We are currently evaluating a psychiatric liaison service to residents of a direct access hostel for homeless women in central London. Of 33 women seen to date, 26 are known to have had at least one previous psychiatric admission, but only four have spent periods of more than one year continuously as inpatients. We believe the current emphasis on deinstitutionalised long stay patients is misplaced: it is the needs of those with chronic, severe psychiatric disabilities in the community and the revolving door patients that are not being addressed. Deferring the closure of psychiatric hospitals ${ }^{2}$ will have little impact on this large group of people. The Department of Health has stated that the forthcoming white paper on community care will contain plans to prevent the unplanned discharge of long stay patients into the community. These safeguards will be of no value to most severely disabled psychiatric patients in the community.

Dr Marshall's findings and our own data both show high levels of unmet need and are in keeping with most surveys of people with psychiatric disorders in the community. These findings clearly indicate inadequate provision of care, but they should not be used as evidence of the ineffectiveness of deinstitutionalisation programmes or properly planned and funded community services. The few controlled studies of selected patients discharged within carefully planned community programmes ${ }^{3}$ show that long term psychiatric patients (whether or not they have had long stay psychiatric admissions) can be maintained outside hospital without the deterioration in symptoms, poor psychosocial functioning, and readmissions that are all too commonly found in the surveys. Perhaps more importantly, the controlled studies in which patients' wishes and satisfaction have been recorded clearly show that they prefer to be treated in the community.

K R LETHEM C R PUGH

Department of Psychiatry,

\section{Middlesex Hospital,}

London WIN 8AA

1 Marshall $M$. Collected and neglected: are Oxford hostels for the homeless filling up with disabled psychiatric patients? BrMed F 1989;299:706-9. (16 September.)

2 Weller BGA, Weller MPI, Coker E, Mahomed S. Crisis at Christmas 1986. Lancet 1987; ; $553-4$.

3 Braun P, Kochansky G, Shapiro R, et al. Overview: deinstitutionalization of psychiatric patients, a critical review of outcome studies. Am 7 P sychiatry 1981;138:736-44.

\section{Safety of Picolax in inflammatory bowel disease}

SIR,-In view of the suggestion of Dr A J G $\mathrm{MCDonagh}$ and colleagues that further evaluation of Picolax is merited ${ }^{1}$ we would like to report our own experience with this preparation in a large cohort of children undergoing fibreoptic colonoscopy at St Bartholomew's Hospital. Between 1982 and 1988 we performed 534 colonoscopies on 412 children attending this hospital and, with few exceptions, Picolax was used routinely to prepare the colon before endoscopy. This included the 287 procedures performed on children with chronic inflammatory bowel disease ( 163 with Crohn's disease, 101 with ulcerative colitis, 23 with indeterminate colitis) that was either known to pre-exist or suspected and confirmed at the time of endoscopy. We found the preparation to be successful for cleansing the bowel and free of major complications.

Based on our experience we have developed the following regimen for preparing the colon before endoscopy in children. The child is given only fluids for 24 hours before the procedure and is given two doses of Picolax, one about 15 hours before endoscopy and the other three hours before. The dose is age dependent: children over 6 years 